\title{
Procollagen I C-propeptide in the cerebrospinal fluid of neonates with posthaemorrhagic hydrocephalus
}

\author{
A Heep, B Stoffel-Wagner, V Soditt, C Aring, P Groneck, P Bartmann
}

See end of article for authors' affiliations

......................

Correspondence to: Dr A Heep,

Universitaetsklinikum Bonn, Abteilung Neonatologie, Perinatalzentrum, Adenaverallee 119 D-53113 Bonn, Germany; a.heep@uni-bonn.de

Accepted for publication 2 January 2002

\begin{abstract}
Background: The pathogenesis of posthaemorrhagic hydrocephalus (PHHC) following intraventricular haemorrhage (IVH) in premature infants includes a fibroproliferative reaction leading to arachnoidal fibrosis, ultimately causing malresorption of cerebrospinal fluid (CSF) at the arachnoid villi.

Aims: To determine whether an increased concentration of the carboxyterminal propeptide of type I procollagen (PICP) in the CSF of neonates after IVH reflects the activation of collagen synthesis preceding the manifestation of PHHC.

Methods: From 20 neonates with PHHC (median birth weight 740 g, median gestational age 25+1 weeks), 52 CSF samples were collected. CSF samples of four neonates (median birth weight $2170 \mathrm{~g}$, median gestational age 32+4 weeks) with congenital non-haemorrhagic hydrocephalus served as controls. PICP was measured by radioimmunoassay.

Results: PICP in CSF taken at the start of external CSF drainage (median day 21, range 17-25 days postnatal age) was significantly increased (median 851.5, range 153.5-1944 $\mu \mathrm{g} / \mathrm{l}$ ) compared with controls (median 136.1, range 33.8-169.5 $\mathrm{\mu g} / \mathrm{ll}$. CSF concentrations of PICP declined until permanent shunt placement (median day 70 , range days 41-113).

Conclusion: In neonates who develop PHHC, significant elevation of PICP concentration in the CSF is present 3-4 weeks after IVH. It reflects the increase of local type I collagen turnover, thereby correlating with manifestation of $\mathrm{PHHC}$.
\end{abstract}

ntraventricular haemorrhage (IVH) occurs in $10-20 \%$ of all infants with a birth weight of less than $1000 \mathrm{g.}^{1-6}$ Development of posthaemorrhagic hydrocephalus (PHHC) is seen in $5 \%$ of these patients. ${ }^{4-8}$ The underlying pathogenesis of hydrocephalus following IVH is not well understood. However, a correlation of the amount of intraventricular blood with the development of PHHC has been proposed.$^{4}$ Local therapies after IVH in neonates, such as fibrinolysis, or steroid application failed to reduce the incidence of shunt dependent PHHC. ${ }^{9-14}$ From the results one may conclude that, apart from the occlusion of the arachnoid villi by blood clots, a fibroproliferative reaction is involved in the pathogenesis of PHHC..$^{15}$ Autopsy findings in adult patients with malresorptive hydrocephalus following aneurysmal subarachnoid haemorrhage $(\mathrm{SAH})$ revealed a fibroproliferative reaction in conjunction with arachnoidal fibrosis. ${ }^{15}$ It is hypothesised that this ultimately led to malresorption of CSF at the arachnoid villi. ${ }^{15}$ Local activation of collagen synthesis is suggested to be the major trigger for the fibroproliferative reaction. ${ }^{17}{ }^{18}$ In experimental models of SAH, increased concentrations of procollagen propeptides of type I and III collagen in the CSF, and leptomeningeal deposition of collagen I and III have been found..$^{19-21}$ The fibre forming collagens (types I-III) are synthesised by mesenchymal cells as procollagens. The amount of type I procollagen released into the extracellular fluid is directly related to the amount of type I collagen fibres formed and deposited in the tissue ${ }^{19}$ CSF concentrations of the carboxyterminal propeptide and aminoterminal propeptide of procollagen I (PICP, PINP) and procollagen III (PIIICP, PIIINP) can be applied as clinical markers of collagen turnover. ${ }^{17} 18$ 22-26

The aim of our study was to analyse the concentration of PICP in the CSF as an indicator of activated collagen turnover after IVH in premature infants who further developed PHHC.

\section{PATIENTS AND METHODS}

This was a prospective study of all premature infants admitted to the two study centres for surgical treatment of PHHC following IVH ( $\mathrm{n}=20$ ). From March 1999 to September 2000 patients were enrolled in the study. Eleven patients were inborn and nine outborn. The patients present a characteristic neonatal risk profile (table 1). Median birth weight was $740 \mathrm{~g}$ and gestational age at birth 25 weeks. By ultrasound all but one patient showed severe intraventricular haemorrhage (III $\%$ $\mathrm{IV}^{\mathrm{O}}$ ) and 9/20 had signs of periventricular leucomalacia (table 1). CSF drainage by ventriculostomy was indicated if one of the following criteria was met: (1) signs of IVH and progressive ventricular dilatation identified by ultrasound (ventricular width $>97 \%$ percentile); (2) excessive enlargement of head circumference ( $>2 \mathrm{~cm} /$ week, daily measurement); (3) bulging fontanel with increasing distance of the sagital suture; and (4) clinical signs of increased ICP (seizures, apnoea-bradycardia, and hypoventilation). ${ }^{8}$

All patients developed a shunt dependent PHHC. CSF samples were therefore taken at week 3 postnatal age, at the time of clinical decompensation of PHHC (median: day 21 postnatal age; range: day 17-25). Further samples were collected at weeks 4 and 5, and at the time of permanent shunt placement when CSF total protein content was normalised (median: day 70 postnatal age; range: day 41-113). Ventricular CSF control samples were collected from four neonates with congenital non-haemorrhagic hydrocephalus at the time of shunt implantation (median birth weight $2170 \mathrm{~g}$, range 1650-2750 g; median gestational age $32+4$ weeks, range $30+0$ to $34+3$ weeks).

All samples were taken from ventricular punctures or subcutaneously placed ventriculostomy reservoirs. CSF was

Abbreviations: $\mathrm{CSF}$, cerebrospinal fluid; IVH, intraventricular haemorrhage; PHHC, posthaemorrhagic hydrocephalus; PICP, carboxyterminal propeptide of type I procollagen; PIIICP, carboxyterminal propeptide of type III procollagen; PINP, aminoterminal propeptide of type I procollagen; PIIINP, aminoterminal propeptide of type III procollagen; $\mathrm{SAH}$, subarachnoid haemorrhage 
Table 1 Neonatal profile of the patients

\begin{tabular}{lll}
\hline Neonatal profile $(\mathrm{n}=20)$ & Number & (\%) \\
\hline Birth weight $(\mathrm{g})$ & $740(470 \text { to } 1685)^{*}$ & \\
Gestational age at birth (weeks) & $25+1(22+3 \text { to } 33+2)^{*}$ & 35 \\
No. boys & $7 / 20$ & 80 \\
Respiratory distress syndrome $>2^{\circ}$ & $16 / 20$ & 45 \\
Seizures & $9 / 20$ & 95 \\
Apnoea-bradycardia syndrome & $19 / 20$ & 5 \\
Necrotising enterocolitis $>2^{\circ}$ & $1 / 20$ & 15 \\
Retinopathy of prematurity $>2^{\circ}$ & $3 / 20$ & 95 \\
Intraventricular haemorrhage, grade $I I I^{\circ}, I^{\circ}$ & $19 / 20$ & 85 \\
$\quad$ Bilateral & $17 / 20$ & 10 \\
$\quad$ Unilateral & $2 / 20$ & 45 \\
Periventricular leucomalacia & $9 / 20$ & \\
\hline \multirow{2}{*}{ Mean (range). } & &
\end{tabular}

\begin{tabular}{|c|c|c|c|c|}
\hline & $\begin{array}{l}\text { Study group } \\
\operatorname{PICP}(\mu \mathrm{g} / /)^{*}\end{array}$ & No. of analyses & $\begin{array}{l}\text { Controls } \\
\text { PICP }\left(\mu \mathrm{g} / \mathrm{ll}^{*}\right.\end{array}$ & $\mathrm{p}$ value** \\
\hline Week 3 & 851 (153-1944) & 14 & & 0.001 \\
\hline Week 4 & $552(83-1588)$ & 13 & & 0.023 \\
\hline Week 5 & $255(67-628)$ & 8 & & 0.2 \\
\hline Shunt & $300(52-946)$ & 17 & $118(33-169)$ & 0.14 \\
\hline
\end{tabular}

immediately centrifuged and stored at $-40^{\circ} \mathrm{C}$ until analysis. PICP was measured with a commercially available radioimmunoassay (Orion Diagnostica, Espoo, Finland). The sensitivity of the method was $1.2 \mathrm{\mu g} / \mathrm{l}$. The intra-assay coefficient of variation was $3.2 \%$ (mean $45 \mathrm{l} \mu \mathrm{g} / \mathrm{l}, \mathrm{n}=16)$, and the interassay coefficient of variation $4 \%$ (mean $435 \mu \mathrm{g} / \mathrm{l}, \mathrm{n}=8$ ).

\section{Data analysis}

For statistical analysis, the Mann-Whitney U test was used, with two sided $p$ values to compare groups of values, as the distributions were non-Gaussian.

\section{RESULTS}

The median concentration of PICP in the CSF of the patients with PHHC taken at week 3 after IVH was raised (median $851.5 \mu \mathrm{g} / \mathrm{l}$, range 153-1944 $\mu \mathrm{g} / \mathrm{l})$. When compared with controls (median $118 \mu \mathrm{g} / \mathrm{l}$, range 33-169 $\mu \mathrm{g} / \mathrm{l}$ ), this difference was statistically significant $(\mathrm{p}<0.001)$. PICP concentrations

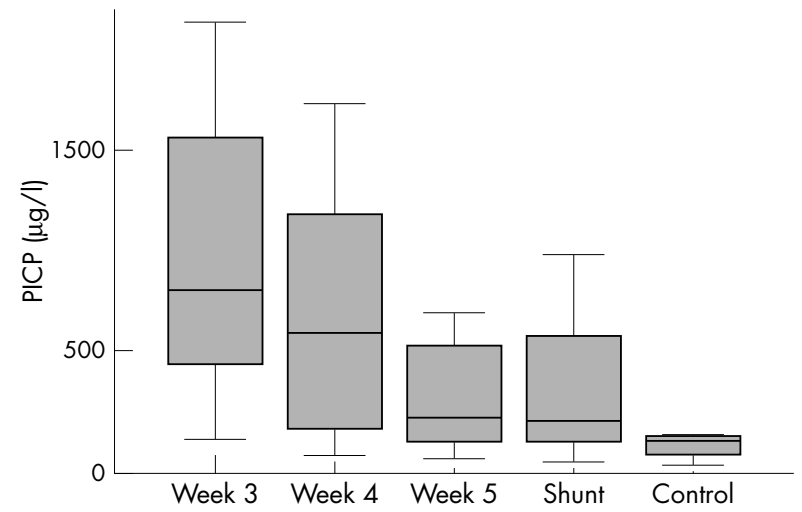

Figure 1 Time course of PICP concentrations in the CSF of 20 neonates with PHHC and four control subjects. Values are median and 25th and 75th centiles (boxes), and 5th and 95th centiles (whiskers). in the PHHC group further decreased at week $4(552 \mathrm{\mu g} / \mathrm{l}$, $83-1588 \mu \mathrm{g} / \mathrm{l})$ and week $5(255 \mu \mathrm{g} / \mathrm{l}, 67-628 \mu \mathrm{g} / \mathrm{l})$, and at the time of shunt placement $(300 \mu g / \mathrm{l}, 52-946 \mu \mathrm{g} / \mathrm{l}$ ) (fig $\mathrm{l}$ and table 2).

\section{DISCUSSION}

The activation of collagen biosynthesis and collagen deposition in the brain after IVH has been shown in humans and in experimental studies in animals (table 3 ). ${ }^{15-18}{ }^{21-25}$ It was shown that up regulation of extracellular matrix protein synthesis in the local mesenchymal cells (dural, leptomeningeal), which are composed of different collagen proteins (type I, type III) was induced as a consequence of cerebral bleeding. ${ }^{15-18} 2327$ Several experimental models show the time course of collagen synthesis activation and fibroproliferative reaction in the brain following SAH. In a rat model of artificial SAH, a threefold increase of meningeal prolyl 4 hydroxylase activity, the major intracellular enzyme of collagen synthesis, was measured one week after induced SAH 17. In the same study, increased collagen synthesis resulted in an accumulation of type l collagen fibres within the meningeal tissue at three weeks after SAH. In a dog model of experimental SAH, leptomeningeal fibrosis was documented after two weeks by histopathology. ${ }^{25}$ In an experimental model of induced lung fibrosis, messenger RNA coding for type 1 procollagen was detected and reached a maximum accumulation two to three weeks after treatment. ${ }^{22}$ Proliferation of leptomeningeal cells and deposition of extracellular matrix in the arachnoid granulation after aneurysmal SAH was shown on human autopsy. ${ }^{18}$ Thus, experimental and human data suggest that IVH may induce collagen synthesis in the CSF and that it is a potential trigger of meningeal fibrosis.

Although most PHHC develop rapidly within two to four weeks after IVH in premature infants, some develop slowly over a period of weeks or months. ${ }^{12813}$

In a recent study, we showed that normalisation of total CSF protein values under daily external ventricular CSF drainage was reached not later than week 5 after IVH. ${ }^{8}$ Procollagen propeptide concentrations decline until permanent 
Table 3 Measurements of collagen turnover in the brain after IVH

\begin{tabular}{llll}
\hline First author & Specimen & Organ & Measurement \\
\hline Sajanti & & \\
Pang $^{21}$ & Rat & Brain & Prolyl 4 hydroxylase \\
Suzuki $^{25}$ & Dog & Brain & Collagen deposition \\
Motohashi $^{18}$ & Dog & Brain & Collagen deposition \\
Sajanti $^{23}$ & Human & Brain & Collagen deposition \\
\hline
\end{tabular}

shunt placement after the start of external CSF drainage, but remain above control concentrations despite normalisation of the CSF protein concentration. As CSF protein content is not an adequate marker for active fibroproliferation, which should therefore be monitored more specifically by determination of PICP. Our data provide evidence for the induction of intrathecal collagen type I turnover by IVH and the involvement of arachnoid fibrosis in the pathogenesis of PHHC in neonates. The results are in accordance with experimental data from animal models (table 3). Raised PICP concentrations in the CSF samples taken at different times show that the increased collagen turnover is not a transient self limiting reaction of tissue repair following injury. It is related to chronically increased collagen turnover and deposition, interfering with CSF drainage and leading in all our patients to at least PHHC.

As all the CSF samples in this study were withdrawn with therapeutic intention, no further serum samples were taken to determine the CSF:serum ratio.

Further investigations are needed to describe the pathophysiology of the activation of collagen turnover after IVH in order to develop therapeutic strategies to prevent malresorptive hydrocephalus caused by meningeal fibrosis.

\section{ACKNOWLEDGEMENTS}

We gratefully acknowledge the valuable discussions with Dr Carlo Schaller

\section{Authors' affiliations}

A Heep, P Bartmann, Department of Neonatology, University of Bonn, Germany

B Stoffel-Wagner, Department of Clinical Biochemistry, University of Bonn

V Soditt, C Aring, P Groneck, Childrens Hospital of Cologne, Germany

\section{REFERENCES}

1 Volpe JJ. Intracranial hemorrhage: germinal matrix-intraventricular hemorrhage of the premature infant. In: Neurology of the newborn. Philadelphia: WB Saunders, 2001:428-93.

2 duPlessis AJ. Posthemorrhagic hydrocephalus and brain injury in the preterm infant: dilemmas in diagnosis and management. In: Seminars in paediatric neurology, Vol 5, No 3. Philadelphia: WB Saunders, 1998:161-79

3 Synnes AR, Chien LY, Peliowski A, et al, and the Canadian NICU Network. Variations in intraventricular hemorrhage incidence rates among Canadian neonatal intensive care units. J Pediatr $2001 ; 138: 525-31$

4 Ahmann PA, Lazzara A, Dykes FD, et al. Intraventricular hemorrhage in the high-risk preterm infant: incidence and outcome. Ann Neurol 1980;7: 118-24.

5 Levene MI, Starte DR. A longitudinal study of posthaemorrhagic ventricular dilatation in the newborn. Arch Dis Child 1981;56:905-10.

6 Papile LA, Burstein J, Burstein R, Koffler H. Incidence and evolution of subependymal and intraventricular haemorrhage: a study of infants with birth weights less than 1,500gm. J Pediatr 1978;92:529-34.
7 Dykes FD, Dunbar B, Lazarra A, Ahmann PA . Posthemorrhagic hydrocephalus in high-risk preterm infants: natural history, management, and long-term outcome. J Pediatr 1989;114:611-18.

8 Heep A, Engelskirchen R, Holschneider A, Groneck P. Primary intervention for posthemorrhagic hydrocephalus in very low birthweight infants by ventriculostomy. Childs Nerv Syst 2001;17:47-51.

9 Luciano R, Velardi F, Romagnoli C, et al. Failure of fibrinolytic endoventricular treatment to prevent neonatal post-haemorrhagic hydrocephalus. A case control trial. Childs Nerv Syst 1997;13:73-6.

10 Hansen A, Whitelaw A, Lapp C, Brugnara C. Cerebrospinal fluid plasminogen activator inhibitor-1: a prognostic factor in posthaemorrhagic hydrocephalus. Acta Pediatr 1997;86:995-8.

11 Hansen AR, Volpe JJ, Goumnerova LC, Madsen JR. Intraventricular urokinase for the treatment of posthaemorrhagic hydrocephalus. Pediatr Neurol 1997; 17:213-17.

12 Whitelaw A. Intraventricular streptokinase after intraventricular hemorrhage in newborn infants. The Cochrane Library. Issue 1. Oxford, 2000.

13 Tortorolo G, Luciano R, Papacci P, Tonelli T. Intraventricular hemorrhage: past, present and future, focusing on classification, pathogenesis and prevention. Childs Nerv Syst 1999;15:652-61.

14 Wilkinson HA, Wilson RB, Patel PP, Esmaili M. Corticosteroid therapy of experimental hydrocephalus after intraventricular-subarachnoid haemorrhage. J Neurol Neurosurg Psychiatry 1974;37:224-9.

15 Massicotte EM, Del Bigio MR. Human arachnoid villi response to subarachnoid hemorrhage: possible relationship to chronic hydrocephalus. J Neurosurg 1999;91:80-4.

16 Kim RC, Talbert WM, Choe W, Choi BH. Massive craniospinal collagen deposition after persistent postoperative intraventricular bleeding. Neurosurgery 1989;24:771-5

17 Sajanti J, Björkstrand AS, Finnilä S, et al. Increase of collagen synthesis and deposition in the arachnoid and the dura following subarachnoid hemorrhage in the rat. Biochim Biophys Acta 1999:1454:209-16.

18 Motohashi O, Suzuki M, Shida N. Subarachnoid hemorrhage induced proliferation of leptomeningeal cells and deposition of extracellular matrices in the arachnoid granulations and subarachnoid space. Immunohistochemical study. Acta Neurochir 1995;136:88-91.

19 Risteli J, Risteli L. Analysing connective tissue metabolites in human serum. Biochemical, physiological and methodological aspects. J Hepatol 1995;22:77-81.

20 Risteli L, Risteli J. Analysis of extracellular matrix proteins in biological fluids. Methods Enzymol 1987;145(part E):391-411.

21 Pang D, Scalabassi RJ, Horton JA. Lysis of intraventricular blodd clot with urokinase in a canine model: Part 3. Effect of intraventricular urokinase on clot lysis and posthemorrhagic hydrocephalus. Neurosurgery 1986; 19:553-72

22 Raghow R, Lurie S, Seyer JM. Profiles on steady state levels of messenger RNAs coding for type I procollagen, elastin and fibronectin in hamster lungs undergoing bleomycin-induced interstial pulmonary fibrosis. J Clin Invest 1985;76:1733-9.

23 Sajanti J, Majamaa K. Detection of meningeal fibrosis after subarachnoid hemorrhage by assaying procollagen propeptides in cerebrospinal fluid. J Neurol Neurosurg Psychiatry 1999;67:185-8.

24 Sajanti J, Heikkinen E, Majamaa K. Transient increase in procollagen propeptides in the CSF after subarachnoid hemorrhage. Neurology 2000;55:359-63

25 Suzuki S, Ishii $M$, Ottomo $M$, et al. Changes in the subarachnoid space after subarachnoidal haemorrhage in the dog: scanning electron microscopic observation. Acta Neurochir 1977;39:1-14.

26 Seibold Weiger K, Wollmann HA, Ranke MB, Speer CP. Plasma concentration of the carboxyterminal propeptide of type I procollagen (PICP) in preterm neonates from birth to term. Pediatr Res 2000;48:104-8

27 Whitelaw A, Christie S, Pople I. Transforming growth factor- $\beta$ 1: a possible signal molecule for posthemorrhagic hydrocephalus? Pediatr Res 1999:46:576-80. 